\section{Revision of Family Medicine Training Requirements: Request to Keep Integrated 4-Year Training Option}

\section{TO THE EDITOR:}

In the September 2019 issue of Family Medicine,${ }^{1} \mathrm{Dr}$ Gravel and colleagues discuss the Accreditation Council of Graduate Medical Education (ACGME) Length of Training Pilot in considerable depth. As graduates of and core faculty in a four year residency program we hope that the ACGME and the American Board of Family medicine will include a length of training option to allow integrated 4-year residency programs to continue.

An integrated training model allows a learner to gain additional skills and expertise all while fortifying core family medicine knowledge. ${ }^{2}$ We both sought to obtain specialized clinical skills (in surgical obstetrics and HIV, respectively) and were able to complete that training within our residency, allowing us to practice as full-spectrum family physicians with specialized expertise. Many family physicians who pursue fellowship have minimal exposure to full-spectrum primary care during fellowship and consequently weaken these skills. In contrast, we are both able to manage complex chronic diseases at a high level with minimal specialist input. We are comfortable with a variety of gynecologic, dermatologic, and orthopedic procedures, as well as point-of-care ultrasound and group medical visits. We prescribe buprenorphine for opioid use disorder. Our panels include pregnant patients as well as children. We participate in quality improvement and original research. Furthermore, we are as comfortable in the hospital as we are in the clinic. We round regularly on adult inpatient medicine (including critically ill ICU patients), labor and delivery, maternity, and inpatient pediatric services. And while we enjoy this broad scope of practice for its own sake, we also recognize that it is protective against burnout.

Thanks to a broad and high-quality scope of training within a 4-year curriculum, we felt confident and competent enough to train residents early in our careers. Confidence in our knowledge base and ability to quickly problem solve were key skills that we suspect we would not have fully developed at the end of a third year of residency training. An integrated curriculum allows for increased time spent in teaching roles for senior residents. We believe that the future of family medicine includes mentoring midlevel clinicians, and we hope that fostering a teaching skill set will establish strong mentors in a variety of primary care careers.

Finally, we believe that enhanced training in family medicine sets physicians up to be exceptional leaders within the health care system. As primary care clinicians who are comfortable in multiple settings and across disciplines, family physicians are well poised to anticipate and resolve problems across the health care system. We each completed a 6 -week clinical chief rotation in our fourth year that taught leadership skills that prepared us for our current leadership roles.

We have benefited significantly from our integrated training and are pleased to be the family physicians that our communities need. As Dr Gravel and his colleagues so rightly stated, students have seen "the elephant in the room" and have started to realize that comprehensive training in full-spectrum family medicine may require more than 3 years of training. We couldn't agree more, and couldn't imagine our practices without it.

doi: 10.22454/FamMed.2021.604909

Joshua St Louis, MD, MPH, AAHIVS

Elise LaFlamme, MD

Lawrence Family Medicine Residency

Lawrence, MA

\section{References}

1. Gravel JW Jr, Rosener SE, Barr WB, Hill KJ. Students See the Elephant. Fam Med. 2019;51(8):638-640. doi:10.22454/ FamMed.2019.280464

2. Carek PJ. The length of training pilot: does anyone really know what time it takes? Fam Med. 2013;45(3):171-172. 


\section{Authors' Response to “Revision of Family Medicine Training Requirements: Request to Keep Integrated 4-Year Training Option"}

\section{TO THE EDITOR:}

On behalf of my coauthors, I thank Drs St Louis and LaFlamme for their personal testimony to the numerous benefits of a 4-year length of training for family medicine. Our specialty has an upcoming decision to make: whether the option for a 4-year integrated training model this letter's authors have experienced should be eliminated or continued. Eliminating the 4-year option would limit student choice to either a 3-year training period or a nonintegrated 1-year, add-on, clinical fellowship model that more often serves to narrow rather than broaden scope of practice. Our crucial discussion would be enriched and better-informed if the voices of those who have actually chosen and/or completed a 4-year integrated family medicine residency were heard. This letter's direct narrative form is powerful evidence that goes far beyond edited responses to study questions that often miss important nuances.

We all should support at least some of our residency programs being able to offer more breadth and (as importantly) depth as described by the authors. Prioritizing workforce quantity over scope is a losing strategy for our specialty; others will be more successful at producing a lower-quality, narrower-scope, but more quickly and cheaply-trained workforce than our 52-year-old 3-year model. Costeffective quality (deriving from preserved and/ or enhanced scope) needs to be our focus; we get diverted and distracted by other considerations at our own peril.

Students do see the elephant in the room, even if we as educators do not. Many potential family medicine residents are choosing other disciplines every year. Students experiencing what Drs St Louis and LaFlamme describe in a 4-year program are attracted to family medicine when the program answers the value proposition with specific, valuable additional skills and knowledge in many different practice areas inherently not obtained in add-on fellowships. This rising tide, providing more space to innovate, would in fact lift all boats if a length-of-training accreditation dam is not built to prevent it.

doi: 10.22454/FamMed.2021.247563

Joseph W. Gravel, Jr, MD, FAAFP

Medical College of Wisconsin

Milwaukee, WI

\section{Adding a Sixth Step: Emphasizing Pharmacists' Roles in Managing Polypharmacy}

TO THE EDITOR:

We thank Drs Tarn and Schwartz for proposing a plan to reduce inappropriate prescribing patterns in their article "Polypharmacy: A Five-Step Call to Action for Family Physicians." More concerning than the drug-drug interactions pointed out by Tarn and colleagues, polypharmacy is associated with several negative health outcomes for older adults, including an increased risk of hospital admissions, adverse drug events, and mortality. ${ }^{2} \mathrm{We}$ applaud the authors' thoughtful suggestions to address polypharmacy. However, we believe a vital sixth step should be highlighted for this call to action: involve pharmacists to reduce polypharmacy and proactively train physicians on ways to prevent medication overutilization.

Pharmacists obtain the doctor of pharmacy (PharmD) degree and may complete optional residency training that allows them to specialize across the patient care continuum and become experienced educators. Regardless of added training, pharmacists can take a larger role in patient care to identify and address all types of medication therapy problems (MTPs), including polypharmacy. It is important for physicians and health care systems to advocate for pharmacists to provide comprehensive medication management in primary care offices, hospital settings, and community pharmacies.

While Tarn and Schwartz discuss pharmacist consultation to address polypharmacy, the scope of pharmacists' contribution is potentially understated. A 2018 Cochrane systematic review acknowledged the importance of pharmacists in reducing potentially inappropriate medications. ${ }^{2}$ Pharmacists working within primary care significantly address polypharmacy, inappropriate medication use, and encourage safer prescribing practices. ${ }^{3}$ Studies have shown that pharmacists in family medicine practices help identify MTPs and yield a significant decrease in the number of inappropriate medications prescribed. ${ }^{3,4}$ Pharmacists have also demonstrated their role in the reduction of polypharmacy outside of primary care. For example, hospital-based pharmacists have successfully reduced the number of patients with polypharmacy while identifying MTPs. ${ }^{5}$ Often not utilized, community pharmacists are also able to optimize medication management 
in older adults. Community pharmacist interventions have resulted in discontinuation of Beers Criteria and other inappropriately prescribed medications. ${ }^{6,7}$

Another area Tarn and Schwartz briefly discuss is educating trainees. Integrating pharmacists throughout medical school and residency education would allow for improved prescribing training and act as a proactive method to prevent polypharmacy. The inclusion of pharmacists in medical education could increase prescriber confidence, reduce inappropriate prescribing, and ultimately reduce avoidable adverse reactions. ${ }^{8}$ Similarly, while it is exciting that over $50 \%$ of family medicine residency programs have clinical pharmacists as faculty, resident education would be enhanced with more universal adoption. ${ }^{9}$

While the steps presented by the authors include pharmacists as a member of the interprofessional team, the extent to which pharmacists are able to assist in optimizing medications is more integral than suggested. We urge family physicians to utilize pharmacists as medication experts to reduce polypharmacy and improve appropriate prescribing, both in direct patient care and teaching roles. Ideally, this would mean hiring pharmacists to primary care offices and family medicine residency programs. Physicians can contact STFM's Pharmacist Faculty Collaborativea working group of clinical pharmacists-as a first step when seeking to add or enhance pharmacist involvement.

doi: 10.22454/FamMed.2021.700569

\section{Lauren Della Grotta, PharmD \\ UPMC St Margaret \\ Pittsburgh, PA}

Sehrish Panjwani, PharmD, BCPS, BCGP

Highmark Health

Pittsburgh, PA

Gregory Castelli, PharmD, BCPS, BC-ADM

UPMC St Margaret

Pittsburgh, PA

\section{References}

1. Tarn DM, Schwartz JB. Polypharmacy: A five-step call to action for family physicians. Fam Med. 2020;52(10):699-701. doi:10.22454/FamMed.2020.909136

2. Rankin A, Cadogan CA, Patterson SM, et al. Interventions to improve the appropriate use of polypharmacy for older people. Cochrane Database Syst Rev. 2018;9(9):CD008165. doi:10.1002/14651858.CD008165.pub4

3. Castelli G, Bacci JL, Dombrowski SK, et al. PharmacistDelivered Comprehensive Medication Management Within Family Medicine Practices An Evaluation of the SCRIPT Project. Fam Med. 2018;50(8):605-612. doi:10.22454/ FamMed.2018.391124
4. Khera S, Abbasi M, Dabravolskaj J, Sadowski CA, Yua $\mathrm{H}$, Chevalier B. Appropriateness of medications in older adults living with frailty: impact of a pharmacist-led structured medication review process in primary care. J Prim Care Community Health. 2019;10:2150132719890227. doi:10.1177/2150132719890227

5. Potter EL, Lew TE, Sooriyakumaran M, Edwards AM, Tong E, Aung AK. Evaluation of pharmacist-led physiciansupported inpatient deprescribing model in older patients admitted to an acute general medical unit. Australas J Ageing. 2019;38(3):206-210. doi:10.1111/ajag.12643

6. Tannenbaum C, Martin P, Tamblyn R, Benedetti A, Ahmed S. Reduction of inappropriate benzodiazepine prescriptions among older adults through direct patient education: the EMPOWER cluster randomized trial. JAMA Intern Med. 2014;174(6):890-898. doi:10.1001/jamainternmed.2014.949

7. Martin P, Tamblyn R, Benedetti A, Ahmed S, Tannenbaum C. Effect of a pharmacist-led educational intervention on inappropriate medication prescriptions in older adults: the D-PRESCRIBE randomized clinical trial. JAMA. 2018;320(18):1889-1898. doi:10.1001/jama.2018.16131

8. Lerchenfeldt S, Hall LM. Pharm.D.s in the midst of M.D.s and Ph.D.s: the importance of pharmacists in medical education. Med Sci Educ. 2018;28(1):259-261. doi:10.1007/s40670017-0520-3

9. Lounsbery JL, Jarrett JB, Dickerson LM, Wilson SA. Integration of clinical pharmacists in family medicine residency programs. Fam Med. 2017;49(6):430-436.

\section{In Response to "Champions of Generalism"}

\section{TO THE EDITOR:}

We thank Dr Saultz for his editorial on generalism. ${ }^{1}$ In response, we offer these additional comments from the perspectives of a community preceptor (J.C.) and a core faculty member (M.T.) with 60 years of combined experience.

Historically, any family physician could join a rural hospital, small-town practice, urban health center, or suburban group, and, with support, meet the needs of their community. True, few performed all aspects of family medicine in their day-to-day work, but we were proud to have the generalist's capability to be nimble and successful in widely diverse settings.

As Dr Saultz notes, generalism has fallen on hard times. Medical knowledge has grown exponentially. No physician can possibly keep up with everything. Family medicine's response to this reality has been mixed. Many residencies struggle with adequate inpatient and obstetric experiences and train family physicians exclusively for ambulatory practice, emphasizing care access and distribution to specialists for anything they cannot handle expediently. The result is that our patients, our colleagues, and we ourselves do not know what to expect of us. Rare today is the physician who identifies 
simply as a family doctor. We are primary care specialists, hospitalists, FM-OBs, palliative care and sports medicine physicians, etc. Pursuing quality, we accept metrics endorsed by specialists and enforced by institutions and insurance companies. Rarely do we perform holistic clinical assessments that honor the generalist core of family medicine. ${ }^{2}$

Yet the vision of family medicine was never to know everything. What we may not know in any one clinical area, we more than make up for with intimate knowledge of our individual patients across problems, settings, and time: their stories, personalities, decision-making styles, family dynamics, and values. This generalist skill set has extraordinary value. ${ }^{3}$ Our fear is that we have sacrificed teaching the value and practice of relationship - the end product of our traditional principles of accessible, comprehensive, continuous, coordinated, and contextual care ${ }^{4}$-in the service of generic, population-based metrics. In a divided world of narrow specialists, we believe that family medicine's generalist expertise is sorely needed.

We offer two ideas. First, we present the idea of the "connected generalist" as a model for family medicine training and practice. In this model, family physicians are not isolated access and distribution doctors but are the center of truly integrated medical communities where they have fewer appointments, provide more comprehensive, continuous, contextual care to their patients, and are directly connected to a cadre of specialists, available electronically in real time, to coordinate complex clinical issues. Modern information technology modalities facilitate this collaborative paradigm shift, and new payment models will compensate both generalists and specialists appropriately for their work. In-person specialty visits and referrals will be fewer, but better. The result will be a real medical home with greater efficiency, lower costs, better outcomes, and more satisfied patients and physicians-all measured holistically.

Second, since words matter, we will all call ourselves family physicians. Some residency graduates may be family physicians with an emphasis on a particular strength, while fellowship graduates will be family physicians with special training in their fellowship area.

Society needs us to rebuild our common identity, honor both our generalist and individual strengths, and take leadership in creating truly integrated medical communities. doi: 10.22454/FamMed.2021.287203

\section{John Clark, MD}

Marc Tunzi, MD, MA

Natividad Medical Center

Salinas, CA

\section{References}

1. Saultz J. Champions of Generalism. Fam Med. 2020;52(10):697-698. doi:10.22454/FamMed.2020.608606

2. Etz RS, Zyzanski SJ, Gonzalez MM, Reves SR, O’Neal JP, Stange KC. A new comprehensive measure of high-value aspects of primary care. Ann Fam Med. 2019;17(3):221230. doi:10.1370/afm.2393

3. Epstein DJ. Range: Why Generalists Triumph in a Specialized World. New York: Riverhead Books; 2019.

4. Saultz JW. Textbook of Family Medicine. New York: McGrawHill; 1999. 